\title{
Maps and Plans of Great Britain
}

\begin{abstract}
A DEPARTMENTAL COMMTTTEE on the A Ordnance Survey was appointed by the Minister of Agriculture and Fisheries on May 28, 1935, under the chairmanship of the Right Hon. Sir John Davidson (now Viscount Davidson), with the following terms of reference :
\end{abstract}

" $(a)$ to consider what measures are necessary to accelerate the revision of the Ordnance Survey Maps in order to bring them up-to-date and thereafter to maintain them at a high level of accuracy, while providing for such other public services as are undertaken by the Ordnance Survey Department;

(b) to consider what immediate steps are possible in the meantime to revise Ordnance Survey Maps to the extent necessary for the purpose of town and country planning schemes ;

(c) to review the scales and styles of Ordnance Survey Maps placed on sale to the public, and to recommend whether any changes are desirable; and

(d) to review the conditions upon which the reproduction of Ordnance Survey Maps is permitted."

At the time, the most pressing problems in these terms of reference were considered to be the provisions of maps for town and country planning, and the question of the condition upon which the reproduction of maps should be permitted, that is, paragraphs $(b)$ and $(d)$; and the Committee accordingly issued an Interim Report* dealing specially with these points, dated December 21, 1935. The final report $\dagger$, dealing with items $(a)$ and $(c)$, was published on November 3 last, although it appears to have been signed so long ago as February 3.

The recommendations are, we believe, more farreaching than those of any of the many previous inquiries which have been held on the Ordnance Survey. It is well known that the basic plans of England on the scale of 1/2500 (popularly known as 25 inches, actually $25 \cdot 344$ inches, to a mile) on which all the maps on smaller scales depend, were plotted as separate projections each embracing a county, or group of counties, having their own independent origins. This resulted in no fewer than thirty-nine separate projections being used for these plans, which comprise 51,456 sheets. That such a system should ever have arisen seems,

* Interim Report of the Departmental Committee on the Ordnance Survey. Pp. 16. (London: H.M. Stationery Office.) 3d. net. See NATURE, May 2, 1936.

† Final Report of the Departmental Committee on the Ordnance Survey (Ministry of Agriculture and Fisheries). Pp. iv $+39+11$ maps. (I.ondon: H.M. Stationery Office, 1938.) 5s. net. to-day, surprising, but it grew up, like many British institutions, in a haphazard way, counties being selected for survey according to their supposed importance irrespective of their geographical situation. Gradually practically the whole country has been surveyed on the 25 -inch scale.

Only the surveyor can really appreciate the inconvenience, not to mention the extra cost involved, especially when maps have to be revised, of this state of affairs. The Committee has fully recognized this, and it is recommended, therefore, "that as soon as it can be conveniently arranged the 1/2500 survey should be re-cast on national instead of county sheet lines on a national projection".

The re-casting of the $1 / 2500$ series will involve the re-drawing of the whole series, which would in any event have been necessary with the majority of the sheets, in order to bring them up to date. The opportunity should therefore be taken, the Committee recommends, of altering the size of the sheets, which would apply to all scales of maps, and introducing a national grid to provide one system of reference for the maps of the whole of Great Britain. This would make it possible to apply a single reference system to all maps by which any point can be precisely defined either on the ground or on the map. The significance of this from a defence point of view, since maps of every part of the country are now liable at any moment to become of military importance, cannot be exaggerated.

It is recommended that the unit for this grid should be the international metre, which has many advantages, being on a decimal system, over any other unit. Under this arrangement the shape of the $1 / 2500$ plans would be square, with one kilometre sides, while the 6 -inch sheet would consist of exactly twenty-five $1 / 2500$ plans. Another advantage of the application of the grid to maps is that it would provide a universal index to maps on all scales, serving the needs both of the general public and of the technical map users. Map sheets would be known by the grid co-ordinates of their south-west corners. The only condition in order to fulfil the function of an index is that the limits of sheets should be coincident with grid lines.

The natural sequence of scales derived from the basic scale of $1 / 2500$, would be $1 / 25,000$ and $1 / 250,000$. The latter differs from the existing $\frac{1}{4}$-inch scale by only $1 \frac{1}{2}$ per cent, a difference scarcely perceptible to the great majority of those 
using this particular scale. The Committee, however, did not see its way to recommending a change, though it does suggest, as an experiment, the introduction of the $1 / 25,000$ as a new scale; with this exception, all the old scales remain the same.

The new scale, which is approximately $2 \frac{1}{2}$ inches to the mile, is of the utmost military importance, and this consideration alone would warrant its introduction. On this map it would be possible, with the help of the national grid, to find quickly and easily the exact distance and azimuth of any one point from another, even should the points fall on different sheets. According to the specimen shown in the Committee's report, contours would be in brown at $5 \mathrm{ft}$. intervals, and we believe, if the detail is not overcrowded, that this scale should prove popular with the general public.

It is a pity the Committee did not see its way to a complete reorganization of the map scales of Great Britain, so as to conform to modern ideas. Doubtless the prejudice in favour of our peculiar form of measurement was considered to be so great that a rational system of map scales would be unacceptable.

The question of revision within a reasonable time of the existing out-of-date $1 / 2500$ plans and their future maintenance was carefully gone into by the Committee. It is considered that air photography should prove useful for this purpose, especially in a country where the surface is altering so rapidly. It is recommended that the Government should consider the formation of a special Air Survey Unit, capable of satisfying the requirements of the Ordnance Survey. Owing to the small numbers of 'photographic days' in the year in Great Britain, it would be necessary to find employment for such a unit in some other part of the Empire during the English winter months. This should not be difficult, as maps and photographs are urgently required for development purposes. It would also be necessary, for the best and most economical results, to build special aircraft suitable for photographic work.

An appendix deals with the proposed national projection and suggests a modified transverse Mercator projection on a central meridian $2^{\circ}$ West as most suitable. The net effect of the adoption of this projection would be to make the scale of plans in the central portion of the country, in the vicinity of the adopted meridian, about 1/2501 $(0.04$ per cent) too small, and the scale of the plans in the extreme east and west coasts about 1/2499 (0.04 per cent) too large, the scale of the intermediate places varying between these limits. A slight variation in scale cannot be avoided in a representation of the curved earth's surface on a plane surface, but these amounts are within the expansion of paper due to variations of atmospheric humidity.

The following is a summary of the Committee's recommendations :

The 1/2500 scale should be retained, and should be re-cast on national instead of county sheet lines on a national projection. While this work is in progress, there should be a general overhaul of the plans to eliminate the errors which have crept into the original survey in course of revision. A national grid should be superimposed on all largescale plans and on smaller scale maps, with certain exceptions, to provide one reference system for the maps of the whole country. The international metre should be adopted as the unit on which the grid should be based, and the large-scale maps in the new national series should be square in shape. The 1/2500 plans when re-published in the new national series should cover one kilometre square of country, while the one inch to the mile and smaller scales should be retained in their existing form. The existing six-inch plates should be retained for printing on demand for special pur. poses. The scale of six inches to the mile should be retained, and maps on this scale should be produced in the new National Series in a square shape and containing twenty-five 1/2500 plans. A new medium scale of $1 / 25,000$ should be tried out experimentally in certain selected areas, and, if successful, should be extended to cover the whole country in a National Series.

It is also recommended that when the revision of the 1/2500 plans has been completed, further investigations should be carried out with the view of establishing whether the requirements of urban areas would not be more adequately met by a survey on the $1 / 1250$ scale. When a suitable opportunity occurs, additional contours should be introduced, and the numbering of parcels should be discontinued as soon as the national grid is introduced. It is also recommended that the Ordnance Survey should continue to publish archæological maps. The existing arrangements for revising the one-inch and smaller scales should continue, but a system of continuous revision should be adopted for the large-scale plans as soon as practicable. Short-term contracts to civil firms, for aerial photographs, should not be continued as a. permanent policy; it is suggested that the Government should consider the formation of a special Air Survey Unit, capable of satisfying the requirements of the Ordnance Survey, as soon as practicable. The Committee also recommends that the position of the Ordnance Survey should be reviewed annually with a view to the maximum practicable recruitment, until the recommendations made have become effective, and that the work should be adequately maintained. 